\title{
Endemic goiter and iodine deficiency status among Guinea-Bissau school-age children
}

\author{
Andre Couto Carvalho $\mathbb{1}^{1,2} \cdot$ Ana Machado ${ }^{3} \cdot$ Adulai Robalo Embalo $^{4} \cdot$ Adriano A. Bordalo $^{3}$
}

Received: 26 August 2017 / Revised: 29 October 2017 / Accepted: 20 November 2017

(c) Macmillan Publishers Limited, part of Springer Nature 2017

\begin{abstract}
Background/objectives Iodine deficiency disorders are estimated to affect $25 \%$ of all school-age children around the world. Current policies concerning iodine deficiency disorders in many countries are not based on robust or recent national data. Our objective was to evaluate the current status of iodine nutrition in Guinea-Bissau (West Africa).

Subject/methods A cross-sectional survey including 299 school-age children, aged 6-14 years old, from four distinct regions of Guinea-Bissau across a coast-hinterland gradient (Bolama, Bissau, Cambaju-Bafatá, and Gabú) was performed. Several iodine deficiency disorders indicators were used: total goiter rate, median urinary iodine concentration (UIC) and regional iodine content in household salt and drinking water samples. Data on the total goiter rate were obtained by thyroid ultrasound.

Results Goiter was found in $73.5 \%$ (CI 95\%, 68.5-78.2\%) of the school-age children. We observed a median urinary iodine concentration of $110 \mathrm{mcg} / \mathrm{l}$, with $7.3 \%$ of the studied population presenting urinary iodine concentration $<50 \mathrm{mcg} / \mathrm{l}$. Only $12.5 \%$ of the household salt samples revealed iodine content $\geq 15 \mathrm{mg} / \mathrm{kg}$. Median well water iodine concentration was 11.7 $\mathrm{mcg} / \mathrm{l}$.

Conclusions Guinea-Bissau presents high rates of goiter in school-age children despite satisfactory median urinary iodine concentration population levels. Salt and drinking water iodine median content cannot explain these findings. Further studies following the progress in iodine deficiency status and the presence of potential goitrogens in diet of this vulnerable population are in needed.
\end{abstract}

A poster with part of this work was presented at the 36th Annual Meeting of the European Thyroid Association, Pisa, Italy in September 2012 and published as an abstract in the Eur Thyroid $J$ 2012;1(suppl 1):75-208.

AndreCouto Carvalho

u08003@ chporto.min-saude.pt

1 Division of Endocrinology, Diabetes and Metabolism. Centro Hospitalar do Porto, Porto, Portugal

2 Life and Health Sciences Research Institute (ICVS), 3B's Associate Institute, University of Minho, Braga, Portugal

3 Laboratory of Hydrobiology and Ecology, Institute of Biomedical Sciences (ICBAS-UP) \& CIIMAR, University of Porto, Porto, Portugal

4 Ayuda, Intercambio y Desarollo (AIDA), Bissau, Guinea-Bissau

\section{Introduction}

Iodine is an essential micronutrient for the production of thyroid hormones, and its deficiency has important effects on the physical and mental development of children [1]. Currently, it is estimated that $>25 \%$ of all school-age children (SAC) worldwide may suffer from iodine deficiency, and are at risk of its complications [2].

The assessment of iodine deficiency disorders (IDD) has been proven difficult, especially in remote populations. For this purpose the World Health Organization (WHO), the United Nations Children's Fund (UNICEF), and the Iodine Global Network (IGN, former International Council for Control of Iodine Deficiency Disorders-ICCIDD), recommend the use of several indicators such as (i) dietary salt iodine content and population use, (ii) median population urinary iodine concentration (UIC), (iii) thyroid size, (iv) dried whole-blood thyroglobulin, and (v) neonatal thyroidstimulating hormone levels [3]. 
In the West African sub-region, goiter is mainly caused by iodine deficiency and by the presence of goitrogens in the diet $[4,5]$. In Guinea-Bissau, one of the poorest countries in the world, endemic goiter was first recognized in 1954 [6], and confirmed 40 years later in two reports [7, 8]. In spite of the lack of recent national data, some effort was placed to introduce iodine supplementation into GuineaBissau population diet after 2004 [9]. However, its impact and the present iodine status are unknown.

The purpose of this study was to assess the status of iodine nutrition in Guinea-Bissau, and to provide much needed data on health indicators for this country to develop a tailored and sustainable strategy to tackle iodine deficiency.

\section{Methods}

A cross-sectional survey of SAC aged from 6 to 14 years was performed in September 2011, in four different regions in Guinea-Bissau, across a coast-hinterland gradient (Bolama, Bissau, Cambaju-Bafatá, and Gabú) (Fig. 1) with an estimated total population of $\sim 901,000$ inhabitants.

Following WHO recommendations, goiter prevalence (evaluated by ultrasound; US), and median UIC determined from spot urine samples in a SAC population [3] were used to investigate the burden of IDD. In addition, anthropometric data were also obtained. The required sample size was estimated between 122 and 489 to be $95 \%$ confident that true iodine urinary excretion would lie within $5 \%$ and $10 \%$ of the obtained value [10]. Sample size required for thyroid volume (Tvol) evaluation was estimated to be 267 , by assuming a goiter prevalence of $50 \%$, with an absolute precision of $5 \%$ and a $90 \%$ confidence interval. An excess of 10 to $15 \%$ sampling was considered for possible missing data.

Casual morning spot $(08-10 \mathrm{~h})$ urine samples were obtained at each location in clean $150 \mathrm{ml}$ plastic cups, aliquoted, and stored in triplicate $2 \mathrm{ml}$ Eppendorf microtubes in an ice chest until analysis. Conventional refrigeration was unavailable owing to the lack of electricity in the grid nationwide, and commercial ice was purchased and replaced every day. In the laboratory, $250 \mathrm{mcl}$ triplicates were assessed spectrophotometrically using a modification of the Sandell-Kolthoff reaction, with an initial ammonium persulfate digestion [11]. A standard curve was obtained for each batch of digested samples. The lab team participate in the ongoing international CDC-Atlanta inter-calibration program Ensuring the Quality of Urinary Iodine Procedures (EQUIP) for the determination of iodine in human urine samples with over $99 \%$ success [12].

Iodine content $\left(\mathrm{KIO}_{3}\right.$ and $\left.\mathrm{KI}\right)$ in household salt purchased in markets at the four locations, was assayed by titration with sodium thiosulfate [13], in triplicate. Water iodine levels were determined by the leuco crystal violet method described in the Standard Methods for the Examination of Water and Wastewater [14]. Triplicates were read at $592 \mathrm{~nm}$ on a Shimadzu UV-1800 Spectrophotometer, and quantified by direct comparison with a calibration curve. In samples with $\leq 10 \mathrm{mcg} / \mathrm{l}$ of iodine, the analysis was repeated, and the standard addition method was applied. All water samples were retrieved from hand dug wells or bore wells used by the studied populations for drinking and food preparation.
Fig. 1 Guinea-Bissau map presenting the four different areas of sampling according to a coast-hinterland gradient (Bolama, Bissau, CambajuBafatá, Gabú)

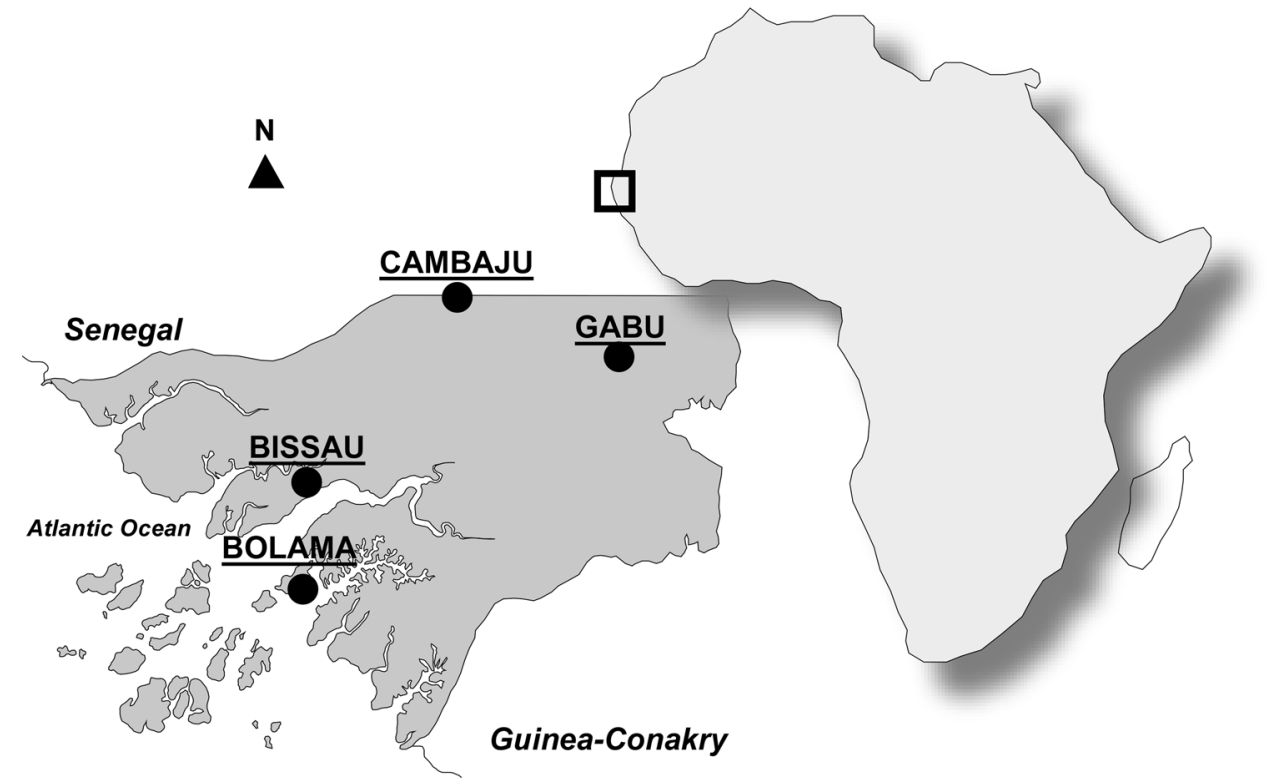


Table 1 Demographic and nutritional characteristics of Guinea-Bissau school-age children sample $(n=299)$

\begin{tabular}{ll}
\hline Characteristic & \\
\hline Age, median year (min-max) & $10.0(6-14)$ \\
Sex, $n$ male (\%) & $151(50.5)$ \\
Nutritional status* & \\
Underweight (WAZ $<-2), n(\%)^{\#}$ & $8(6.8)$ \\
Stunting (HAZ $<-2), n(\%)$ & $18(6.4)$ \\
Low BMI-for-age (BMIZ <-2), $n$ & $72(25.4)$ \\
$(\%)$ &
\end{tabular}

BMIZ body-mass-index-for-age Z-score, HAZ height-for-age Zscore, $W A Z$ weight-for-age $Z$-score

*Nutritional status extracted from the 283 school-age children data and assessed on the basis of the WHO growth reference data from 2007 for children and adolescents aged 5-19 years [18]

${ }^{\#}$ Only calculated for children with $<10$ years old $(n=117)$

Tvol was assessed accordingly to published WHO standards by a trained medical doctor (ACC) with experience on cervical US and certified by the Portuguese Society of Endocrinology [3]. A portable US (Mindray, Shenzhen, P. R. China) equipped with a $60 \mathrm{~mm} 5-10 \mathrm{MHz}$ linear transducer was used for measurements. Subjects were examined in a seated position with extended cervical spine. Maximum perpendicular depth (AP) and width (ML) were measured with electronic calipers on a transverse image of the largest diameter. The maximum lobe length (CC) was measured on a longitudinal image. The transducer was kept perpendicular to the skin. Nodules and/or cystic areas were included in the volume determination. Tvol was estimated according to the method of Brunn et al. [15]. The thyroid gland volume was calculated without isthmus by adding the volume of the right and left lobe, each calculated as follows: Tvol lobe $=$ AP diameter $\times$ ML diameter $\times$ CC diameter $\times$ 0.479 . A thyroid enlargement in a child was regarded as goiter if the Tvol was above the 97th percentile of the bodysurface-area (BSA)-specific international reference values for Tvol in an iodine-replete population [16]. The intraobserver variability was $10.4 \%$ based on a sub-sample of 33 children analysis (data not shown).

Body weight and height were measured using a standardized method of anthropometric techniques [17]. Body weight was measured to the nearest $0.1 \mathrm{~kg}$ using a portable scale. Height was measured to the nearest $0.1 \mathrm{~cm}$ using a portable stadiometer. For nutritional evaluation weight-forage z-score (WAZ), height-for-age z-score (HAZ), and body-mass-index-for-age $\mathrm{z}$-score (BMIZ) were used, based on the 2007 WHO growth reference data for children and adolescents aged 5-19 years [18]. For the purpose of analysis, anthropometric values were only considered suitable after fixed exclusion range of WAZ $<-5$ or $>5$ and HAZ $<-5$ or $>3$ [17]. Children were classified as stunted,
Table 2 Thyroid volume in Guinea-Bissau school-age children as a function of body-surface-area and thyroid-volume-for-BSA above percentile $97(n=298)$

\begin{tabular}{|c|c|c|c|c|c|}
\hline \multirow[b]{2}{*}{$\operatorname{BSA}\left(\mathrm{m}^{2}\right)$} & \multirow[b]{2}{*}{$N$} & \multicolumn{2}{|c|}{ Tvol (ml) } & \multicolumn{2}{|c|}{$\begin{array}{l}\text { Tvol-for-BSA } \\
>\text { P97 }\end{array}$} \\
\hline & & Median & IQR & $n$ & $\%$ \\
\hline 0.7 & 10 & 3.0 & $2.6-4.1$ & 7 & 70.0 \\
\hline 0.8 & 36 & 3.3 & $2.7-4.5$ & 24 & 66.7 \\
\hline 0.9 & 61 & 4.2 & $3.3-4.8$ & 45 & 73.8 \\
\hline 1.0 & 60 & 4.4 & $3.6-5.2$ & 43 & 71.7 \\
\hline 1.1 & 55 & 5.4 & $4.3-6.1$ & 45 & 81.8 \\
\hline 1.2 & 34 & 6.0 & $4.5-7.0$ & 25 & 73.5 \\
\hline 1.3 & 27 & 6.5 & $5.2-8.6$ & 20 & 74.1 \\
\hline 1.4 & 8 & 8.0 & $4.6-9.3$ & 5 & 62.5 \\
\hline 1.5 & 6 & 8.2 & $6.2-11.0$ & 5 & 83.3 \\
\hline 1.6 & 1 & 5.5 & - & 0 & 0.0 \\
\hline Total & $298^{*}$ & 4.6 & $3.7-6.1$ & 219 & 73.5 \\
\hline
\end{tabular}

$B S A$ body-surface-area, $I Q R$ interquartile range, $P 9797$ th percentile, Tvol thyroid volume

International reference values for Tvol-for-BSA are only available for children with BSA between 0.7 and $1.6 \mathrm{~m}^{2}$

*One children with a Tvol of $4.73 \mathrm{ml}$ had lower BSA than $0.7 \mathrm{~m}^{2}$

underweight, or with low BMI-for-age if their HAZ, WAZ or BMIZ was $<-2$, respectively.

Data processing and statistical analyses were carried out using GraphPad Prism version 5.00 for Windows, GraphPad Software (San Diego, CA, USA). Categorical variables were compared using $\chi^{2}$-test or Fisher exact test, as appropriate. One-way analysis of variance with Kruskal-Wallis test and Dunn's multiple comparison post test was used to explore differences between regions. The level of significance was defined as a $p$-value $<0.05$.

\section{Results}

Descriptive data from the SAC are described in Table 1. The total number of SAC studied for spot UIC coupled with thyroid US was 299. Median age was 10 years with a boy: girl ratio of 1:1. Anthropometric analysis was performed in 283 subjects. Seven percent of the children were underweight or stunted, and $25 \%$ had low BMI-for-age.

Tvol distribution as a function of BSA (Tvol-for-BSA) above 97th percentile (P97) is presented in Table 2. The overall prevalence of goiter based on Tvol-for-BSA was 73.5\% (CI 95\%, 68.5-78.2\%), 79.7\% in girls and $67.5 \%$ in boys. Regional goiter rates ranged from $66.7 \%$ (Gabú) to $84.7 \%$ (Bissau), but without statistical significance differences $(p>0.05$, Table 3$)$. The percentage of children with goiter suffering of stunting, underweight, or low BMI-for- 
Table 3 Goiter prevalence and median urinary iodine concentration in the school-age children sample, plus median iodine concentration of household salt and drinking water, from different regions in Guinea-Bissau

\begin{tabular}{lllll}
\hline Region & $\begin{array}{l}\text { Goiter Prevalence, } n(\%, \\
\text { CI 95\% })\end{array}$ & $\begin{array}{l}\text { Median UIC, IQR } \\
(\mathrm{mcg} / \mathrm{l})\end{array}$ & $\begin{array}{l}\text { Median iodine concentration of } \\
\text { household salt, IQR }(\mathrm{mg} / \mathrm{kg})\end{array}$ & $\begin{array}{l}\text { Median iodine concentration in } \\
\text { drinking water, IQR (mcg/l) }\end{array}$ \\
\hline Bolama & $44(73.3,61.7-85.0)$ & $92(64-125)^{*}$ & $9.4(8.2-10.5)^{\#}$ & $2.4(1.7-5.0)^{\S}$ \\
Bissau & $50(84.7,74.6-94.1)$ & $120(86-141)$ & $2.8(2.4-4.1)^{\#}$ & $4.0(0.3-22.5)$ \\
Gabú & $40(66.7,55.0-78.3)$ & $88(67-139)^{*}$ & $4.4(3.8-8.1)$ & $12.0(10.1-15.3)$ \\
Cambaju- & $86(71.7,62.5-80.0)$ & $128(94-169)^{*}$ & $10.4(4.8-23.1)^{\#}$ & $16.2(12.9-19.5)$ \\
Bafatá & & & & $11.7(3.4-17.3)$ \\
Total & $219(73.5,68.5-78.2)$ & $110(103-117)$ & $7.7(1.9-32.5)$ & \\
\hline
\end{tabular}

UIC urinary iodine concentration, IQR interquartile range

$* p<0.05$, Cambaju-Bafatá vs. Bolama or Gabú regions

${ }^{\#} p<0.05$, Bissau vs. Bolama and Cambaju

${ }^{\S} p<0.001$, Bolama vs. Cambaju-Bafatá

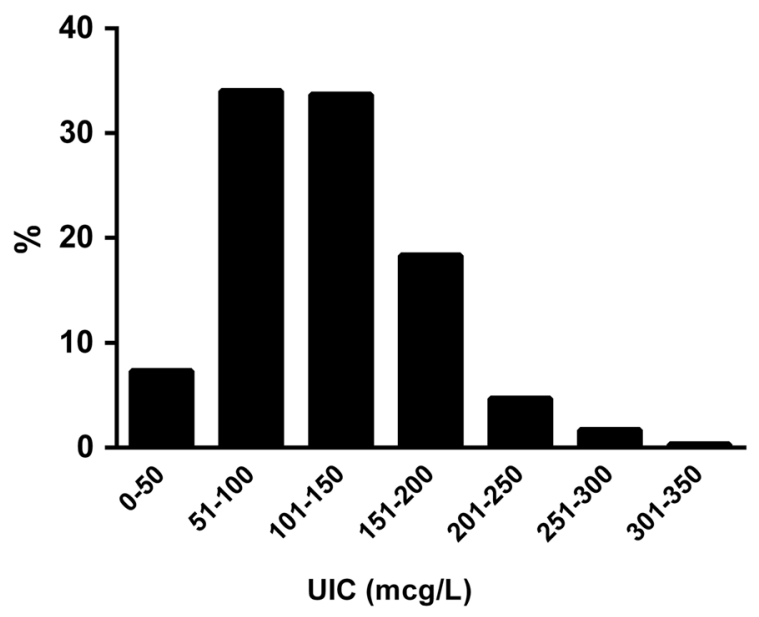

Fig. 2 Frequency histogram of urinary iodine concentration (UIC) in Guinea-Bissau school children $(n=299)$. The median value of UIC was $110 \mathrm{mcg} / \mathrm{l}$ (CI 95\%. 103-117 mcg/l)

age $(69 \%)$ was not different from the one of children with normal nutritional assessment indexes $(p=0.30)$.

The overall median UIC was $110 \mathrm{mcg} / \mathrm{l}$ (CI 95\%, $103-117 \mathrm{mcg} / \mathrm{l})$, with $7.3 \%$ of the studied population presenting UIC lower than $50 \mathrm{mcg} / \mathrm{l}$. The frequency distribution of UIC is shown in Fig. 2. Median UIC values were different between regions with higher values in CambajuBafatá vs. Bolama, an island, and Gabú in the hinterland $(128 \mathrm{mcg} / \mathrm{l}$ vs. 92 and $88 \mathrm{mcg} / \mathrm{l}$, respectively, $p<0.05)$ (Table 3).

Median iodine concentration in household salt was 7.7 $\mathrm{mg} / \mathrm{kg}(n=24$, range $1.9-32.5 \mathrm{mg} / \mathrm{kg})$, with $12.5 \%$ of the samples above the $15 \mathrm{mg} / \mathrm{kg}$ threshold. In drinking water, the median iodine concentration was $11.7 \mathrm{mcg} / \mathrm{l}(n=47$, range $0.3-93.0 \mathrm{mcg} / \mathrm{l})$. Regional differences are presented in Table 3. The lowest values of iodine in household salt were found in Bissau with $2.8 \mathrm{mg} / \mathrm{kg}(p<0.05)$, vs. 9.4 and $10.4 \mathrm{mg} / \mathrm{kg}$ in Bolama and Cambaju-Bafatá, respectively. In the former area salt is harvested locally, whereas in the later is imported from Senegal. In the two hinterland areas (Cambaju-Bafatá and Gabú), water iodine levels were higher $(p>0.05)$ than in the coastal zone (Bissau and Bolama), probably owing to the soil composition, but only Cambaju-Bafatá managed to be significantly different from Bolama (16.2 vs. $2.4 \mathrm{mcg} / \mathrm{l}, p<0.001)$ (Table 3 ).

\section{Discussion}

In the present study, the current IDD status in GuineaBissau was assessed for the first time, by evaluating simultaneous SAC goiter rate (judged by US), median UIC, household iodine salt content and drinking water iodine levels. In the studied SAC population, a $73.5 \%$ rate of goiter with a median UIC of $110 \mathrm{mcg} / \mathrm{l}$ was detected. Also, only $12.5 \%$ of the household salt samples obtained reached the $15 \mathrm{mg} / \mathrm{kg}$ iodine threshold concentration i.e. most of the consumed salt is not iodized.

Our results with SAC goiter prevalence and median UIC values revealed a somewhat inconclusive IDD status for Guinea-Bissau. Since 1992 WHO, UNICEF, and IGN (former ICCIDD) defined that optimal iodine nutrition exists only when the SAC population present a median UIC above $100 \mathrm{mcg} / \mathrm{l}$, with $<20 \%$ of the individuals falling below the $50 \mathrm{mcg} / \mathrm{l}$ threshold [3]. WHO proposal for IDD assessment assumes also that a SAC population with $<5 \%$ total goiter prevalence is free from IDD, and that one with $\geq 30 \%$ is subject to severe iodine insufficiency [3].

By UIC standards, Guinea-Bissau population appears to be iodine-sufficient, but if goiter prevalence is the chosen marker, it should be otherwise classified as a severe iodinedeficient country. This apparent discrepancy of IDD status 
can be partly explained by the fact that these two indicators are complementary and truly assess distinct temporal iodine exposition. UIC is a sensitive marker of recent iodine intake (days), whereas changes in the goiter rate reflect long-term iodine nutrition (months to years). There is no ideal parameter for classifying a population IDD status, mainly because all of them have time-dependence constraints. Recently, the worldwide preferred indicator of iodine nutrition status, i.e., median UIC in SAC, has been challenged as an adequate biomarker of iodine exposure. However, owing to its easy to perform during large population surveys, it rests as an important IDD assessment tool [19].

Only three studies addressing IDD status in GuineaBissau were previously published. In 1954, goiter prevalence (assessed by palpation), in a large adult sample ( $n$ $=87,004)$, was estimated between $0.05 \%$ and $3.1 \%$, with a coastline to hinterland gradient [6]. In 1989, goiter prevalence was determined between 6 and $49 \%$ in a mixed sample of adult and SAC $(n=244)$ [7]. More recently, in 1995, a total SAC goiter rate of $32.6 \%(n=5480)$ was obtained from a national survey that found some regional rates differences, somehow similar to those found in this study observed for Gabú $(68.5 \%, n=1393)$, but not for Bolama $(21.3 \%, n=89)$ [8]. All these earlier studies were based on thyroid palpation and unknown degree of expertize, and therefore their goiter rates are not comparable to the present ones, since our data were obtained by analyzing Tvol evaluated by US, with normative references published by WHO in 2003 [16]. Indeed, the current data have revealed a total goiter rate almost twice the value presented previously. This cannot be explained without taking into account the well-known phenomenon of the Tvol underestimation linked to the palpation method when comparing with a much more sensitive test to detect thyroid enlargement such as cervical US [5, 19]. Current adopted international Tvol-for-BSA references may also contribute for this detected increase of goiter prevalence since it is also known that this published normative values of children Tvol may be over-stated, especially when malnutrition is present $[20,21]$. Tvol obtained by US is also a measurement highly dependent on observer technique and judgment. Interobserver errors were found to contribute to a volume overestimation as high as $30 \%$ on published reference values for Tvol-for-BSA [22]. The presence of this systematic measurement bias on our study cannot be excluded since no inter-observer control was performed. Nevertheless, owing to magnitude of the results presented it seems unlikely that such a bias, if present, would downgrade the goiter severity status in Guinea-Bissau SAC.

It should be also mentioned that total goiter rate, as a marker of chronic IDD, can still be increased many months after successful iodized salt introduction, and iodine nutrition advance, largely because of the long lag-time needed for the improvement or resolution of goiter [19, 23]. Some other environmental and genetic factors may also be involved in regulating Tvol. Higher goiter prevalence rates are common in populations exposed to dietary goitrogens found in food consumed in Guinea-Bissau, such as cassava, millet, sorghum, and peanuts [24, 25]. Moreover, in Guinea-Bissau other nutritional deficiencies known to exacerbate the effects of iodine insufficiency, such as iron and vitamin A are also frequently detected [25-27]. On the other hand, $80 \%$ of well water used by the population for drinking was found to be contaminated with fecal materials [28]. Fecal contamination is also considered to be a goitrogenic factor in drinking water trough bacterial presence, thought to bind iodine and making it unavailable for absorption [29].

Mean UIC can define iodine nutrition status more acutely. The first data on UIC in Guinea-Bissau were obtained in 1989, and revealed a mean iodine content between 17 and $33 \mathrm{mcg} / \mathrm{g}$ creatinine $(n=166)$, consistent with an iodine deficiency status $(<50 \mathrm{mcg} / \mathrm{g}$ creatinine) [7]. Our current work has found an improved mean UIC of $110 \mathrm{mcg} / \mathrm{l}$, reflecting an overall better IDD status. These findings are in line with some recent studies from bordering countries, after 10 years of implementation of a national salt iodizing program. In the Northern neighboring Casamance region (Senegal), and in the Southern Guinea-Conakry the IDD status improved, with SAC median UIC of 145.3 and $139.1 \mathrm{mcg} / \mathrm{l}$, respectively $[4,5,30,31]$.

Human iodine intake is highly dependent on food, salt, and water iodine content. Recommended iodine intake for children aged 6-12 years is $120 \mathrm{mcg}$ per day, and to ensure that all the population in risk of IDD is iodine-sufficient, the WHO recommends the iodization of all human and livestock salt (including salt used in the food industry) to levels of $20-65 \mathrm{mg} / \mathrm{kg}$, based on estimated salt consumption [32, 33]. In 2004, iodizing salt was tentatively produced in Guinea-Bissau and in 2010 iodized salt consumption in Guinea-Bissau (\% households consuming salt with $15 \mathrm{mg} /$ $\mathrm{kg}$ iodine or more) was estimated to be $11.7 \%$ [9, 34]. Our work found a similar percentage in household salt samples (c.a. 12\%) obtained from the different regions. Salt iodization is today the preferred strategy for control of IDD with many countries worldwide having successfully implemented this policy. Nevertheless, it should be acknowledge that only with a continuous monitoring effort and an effective program that tackle also the precarious distribution facilities and other nutritional deficiencies, can salt iodization be sufficient to provide adequate iodine nutrition in low-income countries [35].

Water iodine concentration can be used in some regions as a surrogate marker of environmental iodine deficiency [36]. It not only affects the human direct intake of iodine from water but also influences the iodine content of food 
produced regionally with positive correlation with local population total goiter rate and median urinary iodine excretion [37]. Our data on median regional iodine concentration in drinking water ranged from 2.4 and $16.2 \mathrm{mcg} /$ 1 , in line with some previous reports, but well below other West Africa results [6, 38]. Its current contribute to total iodine intake of SAC in Guinea-Bissau is unknown.

The observed regional disparity, with higher median UIC in Cambadju-Bafatá (hinterland) vs Bolama (coastal island) and Gabú (deeper hinterland), is somewhat puzzling. The worst status of SAC evaluated in the coastal zone can be partly explained by different regional well water iodine concentration, commerce and dietary patterns, and rainfall levels found in these areas. Living in a border village with Senegal (Cambaju-Bafatá), the population has easier access to his neighbor mandatory iodized salt and food supplies, than any of the other studied regions. Endemic goiter is also dependent on genetic and dietary goitrogens consumed. Ethnic origins may be an indication of the variation in genetic susceptibility to iodine deficiency or dependence on other nutritional factors some, of which may be goitrogenic. This could justify some of the lower goiter incidence found in Gabú, where most population is Fulani (as well as in Cambaju-Bafatá), whereas in Bolama the remaining c.a. 20 ethnic groups are well represented [24, 25]. In other African areas with endemic goiter, thiocyanate (SCN), often derived from ingested cassava root, is known to play an etiological role in the development of goiter, especially if associated with iodine deficiency [39]. Studies carried out in the neighboring Casamance region have found iodine/SCN ratios compatible to increased dietary exposure to $\mathrm{SCN}$, but no clear association with the different levels of goiter prevalence and median UIC values was reported [5, 40]. Urinary SCN excretion evaluation was not performed in this study, mostly because cassava is not a food staple in Guinea-Bissau SAC diet.

Some limitations are present in this study. First, there was no stratified random population sampling accordingly to the WHO proposed methods for evaluating and monitoring iodine deficiency status [3]. Logistic issues, time contingency, and many other field difficulties undermined this possibility. Nevertheless, our attempt to include different locations over a coast-hinterland gradient and the overall large number of SAC included can allow an important glimpse of current IDD status on Guinea-Bissau. Second, despite good intra-observer agreement it was not possible to calculate inter-observer variation due to the difficulty of having a trained health worker with cervical US experience available in Guinea-Bissau. Regardless of some possible bias effect, reported by some to achieve up to $36 \%$ variation on Tvol determination, it seems to us very improbable that even if present at such a magnitude it would change Guinea-Bissau IDD status severity [41].
In conclusion, despite the high rate of goiter and the low levels of iodine in household salt, Guinea-Bissau IDD status seems to be better than previously reported. Further studies assessing IDD status in this country are needed for better understanding the current trend. A rigorous evaluation of the existing IDD control program is also warranted with consideration to relaunch the universal salt iodization program. Potable water with iodine supplementation and purification, iodized oil intake, or iodine fortification of seasoning products (like stock cubes), vegetables, and bread may emerge as alternative or complementary methods to iodine deficiency prophylaxis in Guinea-Bissau [25, 42, 43].

Acknowledgements We wish to thank all children and families who agreed to participate in this study; Alfucene Dabo and Víctor Madrigal from Ayuda, Intercambio y Desarollo (AIDA), Bissau-Guinea-Bissau, for the logistic support; Professor Joana Palha from the Life and Health Sciences Research Institute (ICVS), University of Minho, Braga-Portugal, for the portable US; and to Hugo Ribeiro for his technical support with the screening of urine samples.

Compliance with ethical standards This study was conducted according to the guidelines laid down in the Declaration of Helsinki and all procedures involving human subjects were approved by the ICBAS-University of Porto. Verbal informed consent was obtained from all subjects or guardians. Verbal consent was witnessed and formally recorded.

Conflict of interest The authors declare that they have no conflict of interest.

\section{References}

1. ZimmermannMB, BoelaertK.Iodine deficiency and thyroid disorders.Lancet Diabetes Endocrinol. 2015;3:286-295.

2. Zimmermann MB. Iodine deficiency and excess in children: worldwide status in 2013. Endocr Pract. 2013;19:839-846.

3. WHO, UNICEF, ICCIDD. Assessment of iodine deficiency disorders and monitoring their elimination: a guide for programme managers. Geneva: WHO; 2007.

4. Konde M, Ingenbleek Y, Daffe M, Sylla B, Barry O, Diallo S. Goitrous endemic in Guinea. Lancet. 1994;344:1675-1678.

5. Smyth PP, Darke C, Parkes AB, Smith DF, John R, Hetherton $\mathrm{AM}$, et al. Assessment of goiter in an area of endemic iodine deficiency. Thyroid. 1999;9:895-901.

6. Costa FO. Bócio endémico na guiné portuguesa [Endemic goitre in Portuguese-Guinea]. Bol Cult da Guiné Port. 1954;34:243-81.

7. Oliveira AL, Batista JL, Silva AP, Sobrinho LG, Rocha LC. Endemic goitre in Guinea-Bissau. Bull World Health Organ. 1991;69:347-8.

8. Doh A. Rapport d'enquête nationale sur les manifestations de la carence em iode en Guinée-Bissau [Report of the national iodine deficiency survey in Guinea-Bissau]. Organisation de coordenation et de coopération pour la lutte contre les grandes endémies, Centre régional de recherches en alimentation et nutrition, LomeTogo, 1995.

9. International Council for Control of Iodine Deficiency Disorders (ICCIDD). Major push for iodized salt planned for Guinea-Bissau in 2008. IDD Newsletter (February) 2008. 
10. Andersen SKJ, Laurberg P. Variations in iodine excretion in healthy individuals. In: Elsevier (ed.) Comprehensive handbook of iodine, 2009

11. Pino S, Fang SL, Braverman LE. Ammonium persulfate: a safe alternative oxidizing reagent for measuring urinary iodine. Clin Chem. 1996;42:239-43.

12. Centers for Disease Control and Prevention; EQUIP: Ensuring the Quality of Urinary Iodine Procedures. In. https://www.cdc.gov/la bstandards/equip.html, 2017.

13. Sullivan KM, Houston R, Cervinskas J, Gorstein J. Monitoring universal salt iodization programs. World Health Organization. Ottawa: Micronutrient Initiative; 1995.

14. Greenberg AECL, Eaton AD (eds). Standard Methods for the Examination of Water and Wastewater. Washington, DC, USA: American Public Health Association; 1992.

15. Brunn J, Block U, Ruf G, Bos I, Kunze WP, Scriba PC. Volumetric analysis of thyroid lobes by real-time ultrasound (author's transl). Dtsch Med Wochenschr. 1981;106:1338-1340.

16. Zimmermann MB, Hess SY, Molinari L, De Benoist B, Delange $F$, Braverman LE, et al. New reference values for thyroid volume by ultrasound in iodine-sufficient schoolchildren: a world health organization/nutrition for health and development iodine deficiency study group report. Am J Clin Nutr. 2004;79:231-237.

17. Organization WH Physical status: The use and interpretation of anthropometry. Report of a WHO expert committee. WHO 1995; vol. Technical Report Series 854 Geneva.

18. de Onis M, Onyango AW, Borghi E, Siyam A, Nishida C, Siekmann J, Development of a WHO growth reference for schoolaged children and adolescents. Bull World Health Organ. 2007;85:660-667.

19. Zimmermann MB, Andersson M, Assessment of iodine nutrition in populations: past, present, and future. Nutr Rev. 2012;70: 553-570.

20. Henjum S, Barikmo I, Gjerlaug AK, Mohamed-Lehabib A, Oshaug A, Strand TA, et al. Endemic goitre and excessive iodine in urine and drinking water among Saharawi refugee children. Public Health Nutr. 2010;13:1472-1477.

21. Brahmbhatt SR, Brahmbhatt RM, Boyages SC, Impact of protein energy malnutrition on thyroid size in an iodine deficient population of Gujarat (India): Is it an aetiological factor for goiter?. Eur J Endocrinol. 2001;145:11-17.

22. Zimmermann MB, Molinari L, Spehl M, Weidinger-Toth J, Podoba J, Hess S, et al. Toward a consensus on reference values for thyroid volume in iodine-replete schoolchildren: results of a workshop on inter-observer and inter-equipment variation in sonographic measurement of thyroid volume. Eur J Endocrinol. 2001;144:213-220.

23. Zimmermann MB, Hess SY, Adou P, Toresanni T, Wegmuller R, Hurrell RF, Thyroid size and goiter prevalence after introduction of iodized salt: a 5-y prospective study in schoolchildren in Cote d'Ivoire. Am J Clin Nutr. 2003;77:663-667.

24. Moudgal NR, Srinivasan V, Sarma PS, Studies on goitrogenic agents in food. II. Goitrogenic action of arachidoside. J Nutr. 1957;61:97-101.

25. Zimmermann MB, Iodine deficiency. Endocr Rev. 2009;30: 376-408.

26. Thorne CJ, Roberts LM, Edwards DR, Haque MS, Cumbassa A, Last AR, Anaemia and malnutrition in children aged 0-59 months on the Bijagos Archipelago, Guinea-Bissau, WestAfrica: a crosssectional, population-based study. Paediatr Int Child Health. 2013;33:151-60.
27. Biering-Sorensen S, Fisker AB, Ravn H, Camala L, Monteiro I, Aaby $\mathrm{P}$, et al. The effect of neonatal vitamin A supplementation on growth in the first year of life among low-birth-weight infants in Guinea-Bissau: two by two factorial randomised controlled trial. BMC Pediatr. 2013;13:87

28. Bordalo AA, Savva-Bordalo J, The quest for safe drinking water: an example from Guinea-Bissau (West Africa). Water Res. 2007;41:2978-2986.

29. Gaitan E, Goitrogens in food and water. Annu Rev Nutr. 1990;10:21-39.

30. Republique de Guinée, Ministere de la Santé Publique. Rapport de l'evaluation de la lutte contre les TDCI en Guinée [Report of the evaluation of the fight against IDD in Guinea]. Conakry, Guinée, Republique de Guinée, Ministere de la Santé Publique, 2003.

31. Fiorentino M, Bastard G, Sembene M, Fortin S, Traissac P, Landais E, et al. Anthropometric and micronutrient status of school-children in an urban west Africa setting: a cross-sectional study in dakar (senegal). PloS ONE. 2013;8:e84328

32. World Health Organization I, UNICEF. Recommended iodine levels in salt and guidelines for monitoring their adequacy and effectiveness. World Health Organization 1996; WHO/NUT/ 96.13 .

33. Organization WH Guideline: Fortification of Food-Grade Salt with Iodine for the Prevention and Control of Iodine Deficiency Disorders. World Health Organization 2014.

34. UNICEF. Guinea-Bissau Multiple. Indicator Cluster Survey 2010. In. http://data.unicef.org/nutrition/iodine.html, 2010.

35. Cherinet A, Kelbessa U, Determinants of iodine deficiency in school children in different regions of Ethiopia. East Afr Med J. 2000;77:133-7.

36. Fuge R, Johnson CC, The geochemistry of iodine - a review. Environ Geochem Health. 1986;8:31-54.

37. Pedersen KM, Laurberg P, Nohr S, Jorgensen A, Andersen S. Iodine in drinking water varies by more than 100 -fold in Denmark. Importance for iodine content of infant formulas. Eur $\mathbf{J}$ Endocrinol. 1999;140:400-403.

38. Olife IC, Okaka AN, Dioka CE, Meludu SC, Orisakwe OE. Iodine status and the effect of soil erosion on trace elements in Nanka and Oba towns of Anambra State, Nigeria. Ann Chim. 2007;97: 895-903.

39. Bourdoux P, Delange F, Gerard M, Mafuta M, Hanson A, Ermans $\mathrm{AM}$, Evidence that cassava ingestion increases thiocyanate formation: a possible etiologic factor in endemic goiter. J Clin Endocrinol Metab. 1978;46:613-621.

40. Lazarus JH, Parkes AB, John R, N'Diaye M, Prysor-Jones SG. Endemic goitre in Senegal-thyroid function etiological factors and treatment with oral iodized oil. Acta Endocrinol. 1992;126: 149-154.

41. Henjum S, Strand TA, Torheim LE, Oshaug A, Parr CL. Data quality and practical challenges of thyroid volume assessment by ultrasound under field conditions - observer errors may affect prevalence estimates of goitre. Nutr J. 2010;9:66

42. Furnee CA, West CE, van Der Haar F, Hautvast JG. Efficacy of oral iodised oil is associated with anthropometric status in severely iodine-deficient schoolchildren in rural Malawi. Br J Nutr. 2000;84:345-352.

43. Spohrer R, Knowles J, Jallier V, Ndiaye B, Indorf C, Guinot P, et al. Estimation of population iodine intake from iodized salt consumed through bouillon seasoning in Senegal. Ann N Y Acad Sci. 2015;1357:43-52. 